\title{
Effects of aerosol organics on cloud condensation nucleus (CCN) concentration and first indirect aerosol effect
}

\author{
J. Wang ${ }^{1}$, Y.-N. Lee ${ }^{1}$, P. H. Daum ${ }^{1}$, J. Jayne ${ }^{2}$, and M. L. Alexander ${ }^{3}$ \\ ${ }^{1}$ Brookhaven National Laboratory, 75 Rutherford Drive, Upton, NY11973-5000, USA \\ ${ }^{2}$ Aerodyne Research Inc. 45 Manning Road, Billerica, MA 01821-3976, USA \\ ${ }^{3}$ Pacific Northwest National Laboratory, P.O.Box 999, K8-88 Richland, WA 99352, USA \\ Received: 9 April 2008 - Published in Atmos. Chem. Phys. Discuss.: 28 May 2008 \\ Revised: 12 September 2008 - Accepted: 12 September 2008 - Published: 3 November 2008
}

\begin{abstract}
Aerosol microphysics, chemical composition, and $\mathrm{CCN}$ properties were measured on the Department of Energy Gulfstream-1 aircraft during the Marine Stratus/Stratocumulus Experiment (MASE) conducted over the coastal waters between Point Reyes National Seashore and Monterey Bay, California, in July 2005. Aerosols measured during MASE included free tropospheric aerosols, marine boundary layer aerosols, and aerosols with high organic concentration within a thin layer above the cloud. Closure analysis was carried out for all three types of aerosols by comparing the measured $\mathrm{CCN}$ concentrations at $\sim 0.2 \%$ supersaturation to those predicted based on size distribution and chemical composition using Köhler theory. The effect of aerosol organic species on predicted $\mathrm{CCN}$ concentration was examined using a single hygroscopicity parameterization. For aerosols with organics volume fraction up to $70 \%$, such as the marine boundary layer and free troposphere aerosols, CCN concentration and the corresponding first indirect aerosol effect are insensitive to the properties of organics, and can be accurately predicted with a constant hygroscopicity for all organic species. This simplification can facilitate the prediction of indirect aerosol effects using physically-based parameterizations in large scale models. However, for the aerosols within the thin layers above clouds, organics contributed up to $90 \%$ of the total aerosol volume, and an accurate knowledge of the overall organic hygroscopicity is required to accurately predict CCN concentrations. Derivations of organic properties in future closure studies, when aerosols are dominated by organic species, would help constrain the descriptions of organics and aerosol-cloud parameterizations in large scale models.
\end{abstract}

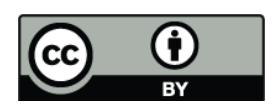

Correspondence to: J. Wang (jian@bnl.gov)

\section{Introduction}

Atmospheric aerosols affect the global energy budget by scattering and absorbing sunlight (direct effects) and by changing the microphysical structure, lifetime, and coverage of clouds (indirect effects). An increase in aerosol concentration would lead to smaller cloud droplet size and higher cloud albedo, i.e. brighter clouds (Twomey, 1977). This effect, which is known as the first indirect aerosol effect, tends to cool the global climate. The smaller cloud droplet size resulting from increased aerosol concentration also inhibits precipitation, leading to an increase in cloud lifetime and coverage, (second indirect aerosol effect, Albrecht, 1989). Although it is widely accepted that the indirect effects can strongly influence the global climate, and potentially mask the warming effect due to anthropogenic $\mathrm{CO}_{2}$, the magnitudes of indirect aerosol effects are poorly understood. The Intergovernmental Panel on Climate Change (IPCC, 2007) considers the indirect effects of aerosols the most uncertain components in forcing of climate change over the industrial period.

A key challenge in quantifying the aerosol indirect effects is to determine the spectrum of cloud condensation nuclei $(\mathrm{CCN})$ and its spatial and temporal variations. CCN's are particles that can grow into cloud droplets at atmospherically relevant supersaturations. At a given supersaturation, $\mathrm{CCN}$ concentration $\left(N_{\mathrm{CCN}}\right)$ is determined by aerosol size distribution and chemical composition. For a particle consisting of inorganic compounds, $\mathrm{CCN}$ activity can be effectively predicted using Köhler theory (Köhler, 1936) based on physicochemical properties of the solute, such as its mass, molecular weight, density, and activity coefficient. However, as ambient particles are often comprised of substantial amount of organic species (Kanakidou et al., 2005), Köhler theory has been extended to include the influence of organic

Published by Copernicus Publications on behalf of the European Geosciences Union. 
species on surface tension (Facchini et al., 1999) and their contributions as solute (Shulman et al., 1996). While laboratory studies have shown that CCN activities of both singleand some multi-component aerosols can be successfully described using extended Köhler theory (Raymond and Pandis 2002, 2003; Bilde and Svenningsson, 2004; Huff-hartz et al., 2006; Svenningsson et al., 2006), the prediction of $N_{\mathrm{CCN}}$ for ambient aerosols remains a challenge. Accurate prediction of $N_{\mathrm{CCN}}$ requires the knowledge of size-resolved composition and mixing state of aerosol, which are often not available for ambient aerosols. Furthermore, ambient aerosols often consist of hundreds of organic species. Despite recent improvements in measurement techniques, a complete speciation of the organic components in ambient aerosols remains very difficult if not impossible. For the prediction of $N_{\mathrm{CCN}}$ in large scale models, the hundreds of organic species cannot be simulated individually due to computational constraints as well as the lack of knowledge of the precursors and formation mechanisms. Furthermore, the properties of many organic species in ambient aerosols (such as the particle density, molecular weight, solubility, and water activity coefficient) are often not available to initiate calculations using extended Köhler theory. As a result, the treatment of aerosol indirect effects needs to be greatly simplified in large scale models including Global Circulation Models (GCM). Some GCM's avoid the calculation of $N_{\mathrm{CCN}}$ by using empirical relationships between aerosol mass and cloud droplet number concentration (Menon et al., 2002). These relationships are based on observations and are easy to implement in global forcing calculations, but they do not reflect the physical processes that occur during cloud nucleation, which depends on the size and chemical composition of the aerosol, as well as the updraft velocity. In addition, these relationships are based on limited measurements, and may not be sufficiently representative for use in global calculation or to predict future scenarios. More rigorous approaches, which are also more computationally intensive, are parameterizations that are based on particle size distribution, chemical composition, and Köhler theory (e.g. Abdul-Razzak and Ghan, 2000). However, due to the inability to resolve individual species in global models, the description of organic species is often greatly simplified, such as by assuming a constant hygroscopicity for all organics (Takemura et al., 2005).

The relationships among particle size distribution, chemical composition, and the ability of particles to serve as "CCN" have also been examined in a number of closure studies, which compared $N_{\mathrm{CCN}}$ predicted using measured ambient aerosol size distribution and composition to that directly measured. An overview of the results from previous closure studies can be found in Broekhuizen et al. (2006) and Medina et al. (2007). In these closure studies, a variety of simplified representations of particle composition and organic properties were necessary due to a limited knowledge of the identity and properties of these organic species. Therefore, these closure studies also provided tests for pre- dicting $N_{\mathrm{CCN}}$ using extended Köhler theory and simplified description of aerosol organics, which is necessary in large scale models. In many closure studies, organics are assumed to be insoluble (Liu et al., 1996; Chuang et al., 2000; Cantrell et al., 2001; Roberts et al., 2002; Snider et al., 2003; Broekhuizen et al., 2006; Rissman et al., 2006; and Medina et al., 2007). Other studies used different simplifications of aerosol chemical composition. For example, Van Reken et al. (2003) assumed particles observed during CRYSTALFACE study were pure ammonium sulfate, which was generally supported by Aerosol Mass Spectrometer (AMS) measurements. Roberts et al. (2002) also assumed about half of the organics were water soluble (e.g. dicarboxylic acids). Stroud et al. (2007) represented the organics as a mixture of levoglucosan, pinic acid, and fulvic acid. However it was found that assuming insoluble organics resulted in better agreement between the predicted and measured $N_{\mathrm{CCN}}$. While closure was achieved for all or most of the data sets in some of the studies (Liu et al., 1996; Cantrell et al., 2001; Roberts et al., 2002; Van Reken et al., 2003; Broekhuizen et al., 2006, and Medina et al., 2007), others showed substantial discrepancies (Chuang et al., 2000; Rissman et al., 2006, and Stroud et al., 2007). In general, better closure agreements were achieved when the aerosols were not strongly influenced by anthropogenic emissions and contained low organic content. The difficulty in achieving closure in some of the studies could be due to a number of reasons. First, the CCN measurements could have substantial uncertainties and/or biases. Second, aerosol chemical composition measurements in some of the earlier closure studies were often crude and incomplete. In addition, for aircraft-based measurements, slow measurement techniques could have also contributed to the failure to achieve closure due to the spatial variability.

In this work, $\mathrm{CCN}$ closure studies were conducted using data collected during the Marine Stratus/Stratocumulus Experiment (MASE). Due to their extensive spatial coverage and high susceptibility, marine stratus/stratocumulus is considered a major contributor to first indirect aerosol effect. Based on sampling location, the aerosols observed during MASE were classified into three different types, which showed very different chemical characteristics. CCN concentrations at $\sim 0.2 \%$ supersaturation were predicted using measured aerosol size distribution and chemical composition, and compared to simultaneously measured $N_{\mathrm{CCN}}$ for the three aerosol types observed. The closure study was performed assuming a wide range of organic properties, which is represented using a single hygroscopicity parameterization. The sensitivity of the predicted $N_{\mathrm{CCN}}$ to organic properties is examined. Theoretical analysis was also carried out to explore the feasibility of predicting $N_{\mathrm{CCN}}$ and the first indirect aerosol effect using a simplified representation of organic species. The accuracy of predicted $N_{\mathrm{CCN}}$ and the first indirect aerosol effect when using the simplified representation is examined. 


\section{Measurements}

The Marine Stratus/Stratocumulus Experiment (MASE) field campaign was carried out in July 2005 off the coast of Northern California between Monterey and Pt. Reyes, to study the aerosol-cloud interactions in the climatically important regime of the eastern Pacific marine stratocumulus (Daum et al., 2008). The Department of Energy (DOE) Gulfstream1 (G-1) aircraft flew a total of 11 scientific flights. All G-1 sampling flights originated from Sacramento, CA where the aircraft was based. The flight strategy was to climb to an altitude of $\sim 1.5 \mathrm{~km}$ or more after takeoff from Sacramento and head west towards Pt. Reyes, where the mobile facility of the DOE Atmospheric Radiation Program (ARM) was deployed. Upon completion of sampling at Pt. Reyes, the aircraft headed offshore, and flew repetitive multi-altitude patterns (about $10-15 \mathrm{~min} / \mathrm{leg}$ ) with legs above cloud, at multiple altitudes in-cloud, and if possible, below cloud.

During MASE, the G-1 carried a suite of instrumentation to measure the microphysics and chemical composition of aerosol, cloud microphysics, state parameters (i.e., ambient temperature, pressure, relative humidity, etc.), winds, and radiation fields. Only the measurements related to this study are discussed below. Aerosol size distribution was measured by a Scanning Mobility Particle Sizer (SMPS) (Wang et al., 2003). The major components of the SMPS are a cylindrical Differential Mobility Analyzer (Model 3081, TSI Inc., Minneapolis, Minnesota) and a Condensation Particle Counter (Model 3010, TSI Inc., Minneapolis, Minnesota). Prior to measurements, the relative humidity (RH) of aerosol sample was reduced to below $25 \%$ inside a Nafion drier. Aerosol size distribution ranging from $15 \mathrm{~nm}$ to $\sim 450 \mathrm{~nm}$ was measured every $60 \mathrm{~s}$. The SMPS was calibrated using polystyrene latex standards. Data from the SMPS were reduced using the data inversion procedure described by Collins et al. (2002).

CCN concentration at $\sim 0.2 \%$ supersaturation was measured by a CCN counter (Droplet Measurement Technology, Boulder). Prior to MASE, the DMT CCN counter was calibrated using ammonium sulfate at a pressure of $920 \mathrm{hPa}$, a temperature (measured at the first temperature control stage) of $30^{\circ} \mathrm{C}$, a flow rate of $0.65 \mathrm{~L} \mathrm{~min}^{-1}$, and a temperature gradient of $4^{\circ} \mathrm{C}$. Based on this calibration, the supersaturation was derived as $0.22 \%$ from Kohler theory using a constant van't Hoff factor of 2.5 for ammonium sulfate. During MASE, the temperature gradient and flow rate were maintained the same as during the calibration. However, both pressure and temperature varied as aircraft changed altitude. Roberts and Nenes (2007) showed that the supersaturation inside DMT CCN counter is proportional to the pressure, which is also in agreement with the data presented by Rose et al. (2008). In our analysis of MASE CCN data, the supersaturation was corrected for pressure change as $0.22 \% \cdot\left(\frac{P}{920 \mathrm{hpa}}\right)$, where $P$ is the pressure inside the $\mathrm{CCN}$ counter during the flights. The effect of temperature on su- persaturation is significantly smaller than that of pressure for the measurements during MASE. During MASE, the CCN sampling temperature varied mostly from 31 to $36^{\circ} \mathrm{C}$, i.e. 1 to $6^{\circ} \mathrm{C}$ above the temperature during the calibration. Such an increase in temperature leads to a decrease of supersaturation by $\sim 1.6 \%$ to $\sim 9.6 \%$ (relative). This corresponds to a decrease of supersaturation from $0.22 \%$ to $0.2 \%-0.216 \%$, and is well within the uncertainty of calibration. Therefore, the small effect of temperature on supersaturation is neglected in our analysis. After correction for pressure change, the supersaturation ranged from $0.17-0.23 \%$ during MASE, which is within the typical supersaturation range of stratocumulus clouds. The $\mathrm{CCN}$ counter consists of a cylindrical continuous-flow gradient diffusion chamber. A constant stream-wise temperature gradient is applied such that the difference between water vapor mass diffusivity and air thermal diffusivity leads to a quasi-uniform centerline supersaturation. CCN's, which are confined near the centerline, grow into super-micrometer droplets and are detected by an Optical Particle Counter downstream (Roberts and Nenes, 2005). The CCN data during the descent and ascent of G-1 were excluded from this analysis, as the pressure change inside the CCN counter led to instability of sample flow and supersaturation.

The size-resolved chemical composition of ambient aerosol was determined using an Aerodyne quadrupole aerosol mass spectrometer (AMS, Jayne et al., 2000). The details of the AMS operation onboard the G-1 have been given in detail in Kleinman et al. (2007), and will be only briefly described here. The AMS operation alternates between pTOF (particle time of flight) and MS (mass spectrum) modes. In the pTOF mode, the particle beam is chopped and the particles are sized according to their flight time between the chopper and a particle vaporizer. In the MS mode, the chopper moves in and out of the aerosol sample beam to provide total and background signals, which allow the total mass concentrations to be deduced. For most flights, the sampling average time was $30 \mathrm{~s}$, which was split between the pTOF and MS modes. The AMS analysis software (Allan et al., 2004) determines concentration from MS mode and partitions that concentration into size bins according to the pTOF measurements. Measurement of aerosol species depends on the aerosol impinging on the particle vaporizer, after which it is vaporized, ionized and detected by a quadruple mass filter. During MASE, the temperature of the vaporizer was $600-650^{\circ} \mathrm{C}$, adequate to vaporize mixed $\mathrm{SO}_{4}^{2-}-\mathrm{NO}_{3}^{-}-\mathrm{NH}_{4}^{+}$ salts and organic compounds which together are expected to constitute most of the mass for the particles with diameters less than $500 \mathrm{~nm}$. Refractory materials such as $\mathrm{NaCl}$, mineral dust, or blackcarbon are not detected by the AMS. For 9 of the total 11 research flights during MASE, valid data were available for all three measurements described above. 


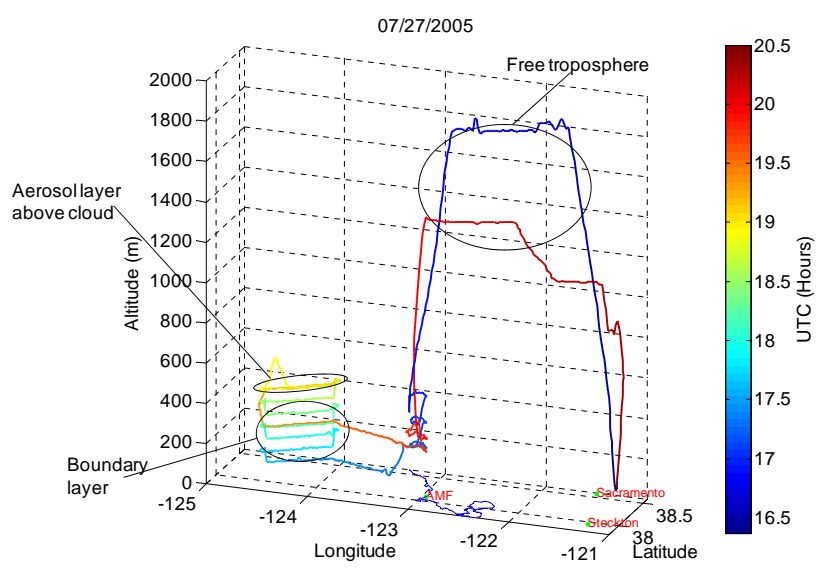

Fig. 1. The flight track of G-1 on 27 July 2005 and the classifications of aerosol types.

\section{Data overview: typical aerosols observed during MASE}

Aerosols observed during MASE were grouped into three major types based on the sampling altitude and the characteristics of aerosol microphysics and composition. The first was "Free Troposphere (FT)" aerosol observed during the ferries between Sacramento and Pt. Reyes (Fig. 1). The ferries were mostly at an altitude of $1500 \mathrm{~m}$ or higher and were above the boundary layer except on 7/18/2005 and 7/19/2005. Figure 2 shows the size distributions of total number, $\mathrm{SO}_{4}^{2-}, \mathrm{NO}_{3}^{-}$, and organics measured during the ferries on 7/27/2005 and $7 / 18 / 2005$. The size distributions of the FT aerosols were often unimodal (Fig. 2a), and the aerosol mass loading was typically very low (e.g. less than $1.4 \mu \mathrm{g} / \mathrm{m}^{3}$ on $7 / 27 / 2007$ ). Due to the low FT aerosol mass loading and the short average time associated with FT measurements, the mass size distributions of chemical species measured by the AMS were quite noisy (Fig. 2c). However, aerosols observed during the ferry flights on 7/18/2005 and 7/19/2005 showed much higher number and mass concentrations, which were likely due to the upward mixing of boundary layer pollution. During MASE, the composition of FT aerosols was dominated by sulfate and organics, and the contribution from nitrate was small. The size distributions of sulfate and organics exhibited a similar shape based on the measurements on 7/18/2005 and $7 / 19 / 2005$, which had higher counting statistics due to elevated aerosol mass concentrations.

"Boundary layer (BL)" aerosols were sampled over the Pacific at multiple altitudes within the boundary layer. Two examples of typical BL aerosols observed are shown in Fig. 3. Aerosol size distributions were often bimodal, with the modal diameters of the Aitken and accumulation modes near 60 and $160 \mathrm{~nm}$, respectively. Similar to the FT aerosols, sulfate and organics dominated the composition of the BL aerosols, and the shapes of the sulfate and organic size distributions were similar.
During MASE, a thin layer of aerosol with high mass concentration was frequently observed just above the cloud. Aerosol within this thin layer, which was often $\sim 60 \mathrm{~m}$ thick, is referred to as the "Above Cloud (AC)" type. Figure 4 shows aerosol composition within the thin layer was dominated by the organics, especial for particles with diameters less than $200 \mathrm{~nm}$. Unlike the FT and BL aerosols, the size distribution of organics was quite different from that of sulfate. The sulfate mass concentration often reached its maximum at vacuum aerodynamic diameter of $\sim 600 \mathrm{~nm}$, which was substantially larger than the peak size of the organics.

\section{CCN closure study}

\section{$4.1 \kappa$-Köhler theory}

In our closure studies, the critical dry diameter that corresponds to activation at $\sim 0.2 \%$ supersaturation was calculated using the " $\kappa$-Köhler theory" (Petters and Kreidenweis, 2007), which uses a single parameter $\kappa$ to describe the Raoult effect on CCN activation. In $\kappa$-Köhler theory, the water vapor saturation ratio over the aqueous solution droplet $S$ is given by:

$S=\frac{D^{3}-D_{p}^{3}}{D^{3}-D_{p}^{3}(1-\kappa)} \exp \left(\frac{4 \sigma_{w} M_{w}}{R T \rho_{w} D}\right)$

where $D$ is the droplet diameter, $D_{p}$ the dry diameter of the particle, $M_{w}$ the molecular weight of water, $\sigma_{w}$ the surface tension of aqueous solution, $\rho_{w}$ the density of water, $R$ the gas constant, $T$ the absolute temperature. For particles comprised of multiple components, the value of $\kappa$ is given by a simple mixing rule (Petters and Kreidenweis, 2007):

$\kappa=\sum_{i} x_{i} \kappa_{i}$

where $x$ is the volume fraction and subscript $i$ denotes species $i$. For soluble inorganic species, such as $\mathrm{NH}_{4} \mathrm{HSO}_{4}$, $\mathrm{NH}_{4} \mathrm{NO}_{3,} \kappa_{i}$ can be derived as:

$\kappa_{i}=v_{i} \frac{\rho_{i} M_{w}}{\rho_{w} M_{i}}$

where $\rho$ is the density, $M$ the molecular weight, and $v$ the van't Hoff factor. The van't Hoff factor takes into consideration the non-idealities of water activity, and the values used in this study are 2.5, 2.5, and 1.9 for $\left(\mathrm{NH}_{4}\right)_{2} \mathrm{SO} 4, \mathrm{NH}_{4} \mathrm{HSO}_{4}$, and $\mathrm{NH}_{4} \mathrm{NO}_{3}$, respectively (Clegg et al., 1998; Petters and Kreidenweis, 2007).

The derivation of $\kappa$ from experimental data is based on the assumption that $\sigma_{w}=0.072 \mathrm{Jm}^{-2}$ (pure water, Petters and Kreidenweis, 2007). The derived $\kappa$ is positively biased for surface active organic species due to this assumption. However, in calculation of $\kappa$ for a mixture containing the same surface active species, the larger $\kappa$ of the organic species partially compensates for the lower surface tension of the 

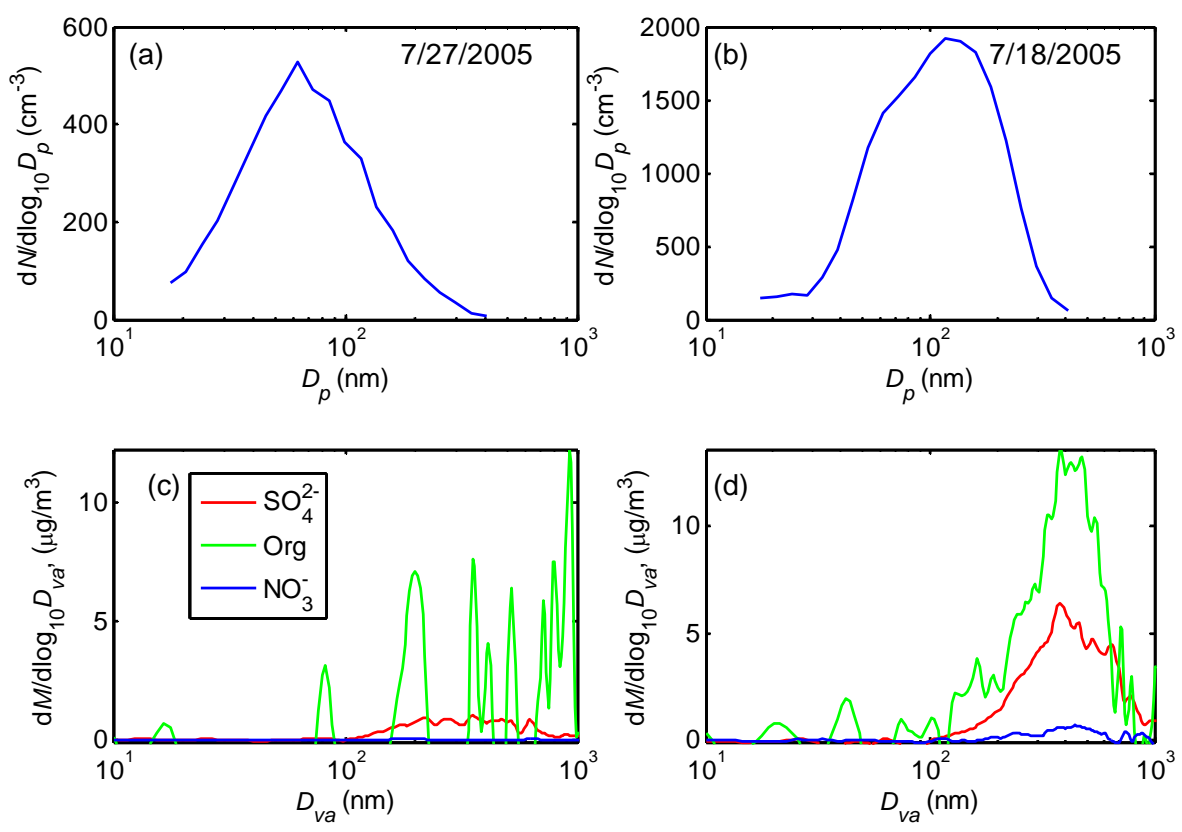

Fig. 2. Aerosol number size distribution (a and b) and mass size distributions of $\mathrm{SO}_{4}^{2-}$, organics, and $\mathrm{NO}_{3}^{-}$(c and d) for aerosols observed during ferry flights on 7/27/2005 (a and c) and 7/18/2005 (b and d).
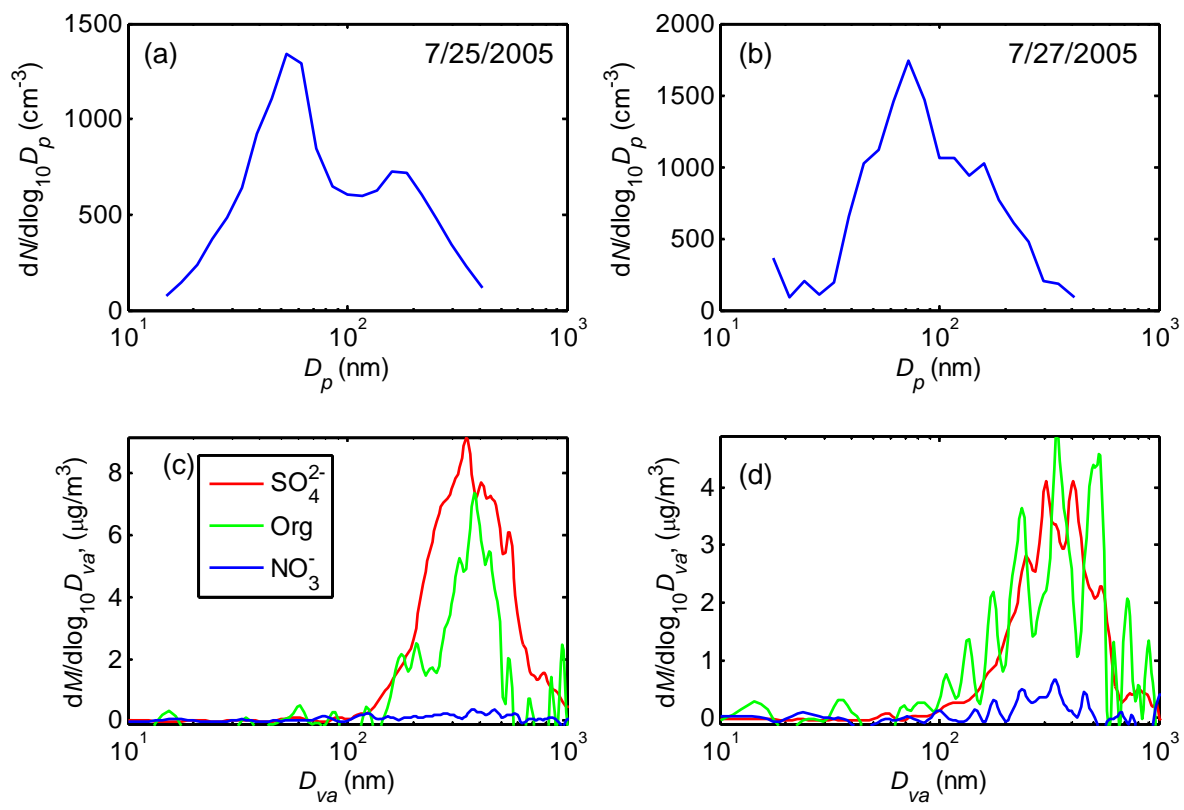

Fig. 3. Aerosol number size distribution (a and $\mathbf{b})$ and mass size distributions of $\mathrm{SO}_{4}^{2-}$, organics, and $\mathrm{NO}_{3}^{-}(\mathbf{c}$ and $\mathbf{d})$ for aerosols observed in boundary layer over ocean on 7/25/2005 (a and c) and 7/27/2005 (b and d).

mixture. Although this approach is not thermodynamically rigorous, Petters and Kreidenweis (2007) showed that it predicts the hygroscopicity within measurement uncertainty for mixtures that contain both surface active species and surface inactive compounds. In addition, at the critical droplet diameter that corresponds to the maximum supersaturation at the droplet surface, the concentration of surface active organics is often very low due to the large water mass. As a result, the effect of surface active organic species is usually small except for organics with extreme properties (Ervens et al., 2005). 

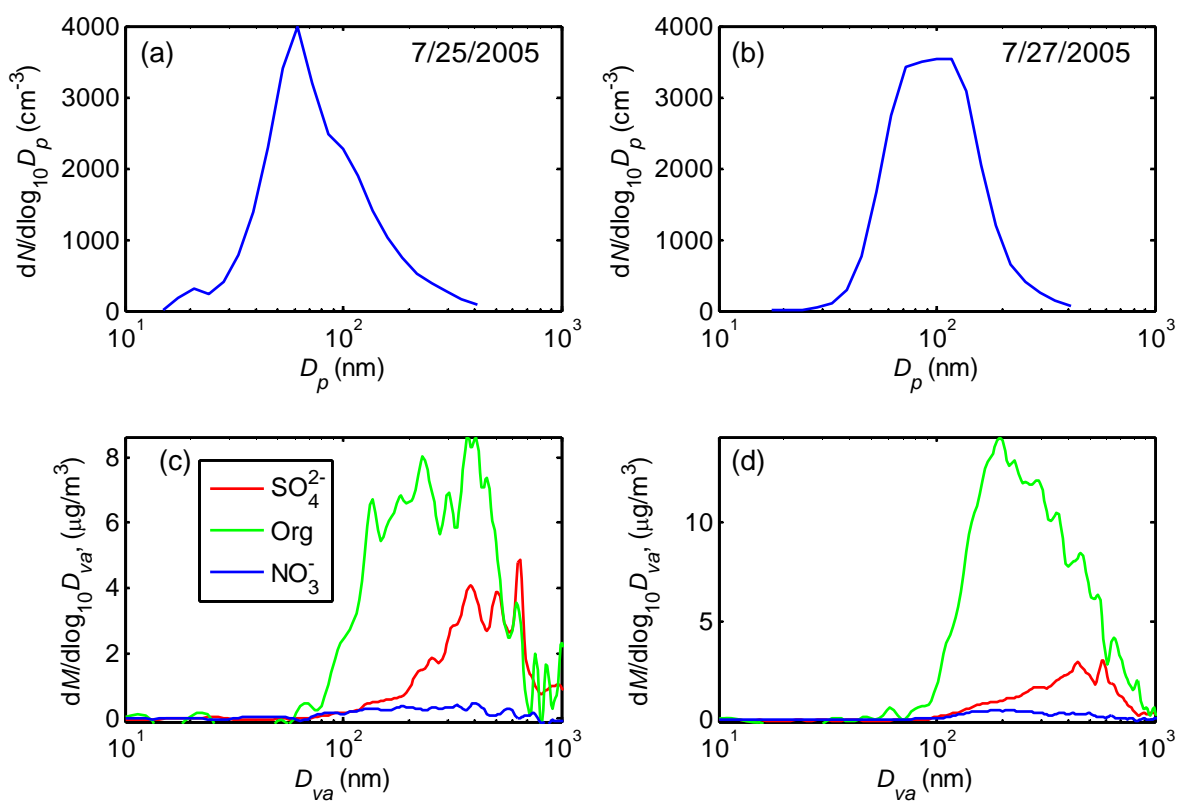

Fig. 4. Aerosol number size distribution (a and $\mathbf{b})$ and mass size distributions of $\mathrm{SO}_{4}^{2-}$, organics, and $\mathrm{NO}_{3}^{-}$(c and $\left.\mathbf{d}\right)$ for aerosols observed in thin layers above clouds on 7/25/2005 (a and c) and 7/27/2005 (b and d).

\subsection{Derivation of aerosol chemical composition from AMS measurements}

While AMS represents a significant improvement over traditional filter-based techniques, its characterization of aerosol composition is still incomplete. To carry out CCN closure study, we constructed aerosol chemical composition from the AMS data using following approach. First, the aerosols were considered consisting mainly of $\mathrm{SO}_{4}^{2-}, \mathrm{NO}_{3}^{-}, \mathrm{NH}_{4}^{+}$, and Organics. This assumption should be valid for the aerosols observed in the free troposphere and in the thin layers above clouds. The BL aerosols might contain substantial amount of sea salt. Previous studies show that the typical dry mode diameter of sea salt particle size distribution is greater than $300 \mathrm{~nm}$, and the typical concentration of sea salt over ocean is often less than $10-20 \mathrm{~cm}^{-3}$ (Lewis and Schwartz, 2005). It is expected that sea salt is present mainly in large particles, which contribute to only a small fraction of CCN due to their low number concentrations. Therefore, although sea salt could contribute to the total aerosol mass concentration, neglecting the sea salt should not lead to an appreciable error in predicted $N_{\mathrm{CCN}}$. Observed $\mathrm{NO}_{3}^{-}$was assumed to exist as $\mathrm{NH}_{4} \mathrm{NO}_{3}$, and $\mathrm{SO}_{4}^{2-}$ is assumed as $\mathrm{NH}_{4} \mathrm{HSO}_{4}$. This picture is consistent with the average concentration of $\mathrm{SO}_{4}^{2-}, \mathrm{NO}_{3}^{-}$, $\mathrm{NH}_{4}^{+}$observed during MASE. Given the similar $\mathrm{CCN}$ activity of $\left(\mathrm{NH}_{4}\right)_{2} \mathrm{SO}_{4}$ and $\mathrm{NH}_{4} \mathrm{HSO}_{4}$, the uncertainty associated with these assumptions is expected to be small. The sensitivity of the predicted $N_{\mathrm{CCN}}$ to this assumption is discussed further below.
For the FT and BL aerosols, the size spectra of sulfate and organics showed a similar shape and the aerosol composition was dominated by sulfate and organics. Therefore, aerosol chemical composition was treated as independent of particle size with all species internally mixed. This assumption allowed derivation of volume fraction of each species using the AMS MS-mode measurements, which have much higher signal to noise ratio than the pTOF-mode measurements. During MASE, the average volume fraction for ammonium bisulfate, nitrate, and organics were $43 \%, 7 \%$ and $50 \%$ for the FT aerosols, and $51 \%, 3 \%$, and $46 \%$ for the BL aerosols.

For the AC aerosols, the shapes of sulfate and organic size distributions were quite different. To describe this size dependence of chemical composition, we assume the AC aerosols to be external mixtures of internally mixed lognormal modes, and that within each mode, all species are internally mixed and the chemical composition of the mode was constant, independent of particle size. The mode diameter, concentration, geometric standard deviation, and the mass fraction of each species were derived for each mode using the approach described as follows. First, the total mass size distribution was fitted by lognormal modes (two modes for the example given in Fig. 5a). Second, the size spectra for the three species $\left(\mathrm{NH}_{4} \mathrm{HSO}_{4}, \mathrm{NH}_{4} \mathrm{NO}_{3}\right.$ and organics) were each expressed as a linear combination of the lognormal modes determined from the total aerosol mass. The linear coefficients, which are the mass fractions of individual species within the lognormal modes, were determined using a least square fitting procedure. Figure 5 shows that the fitted 

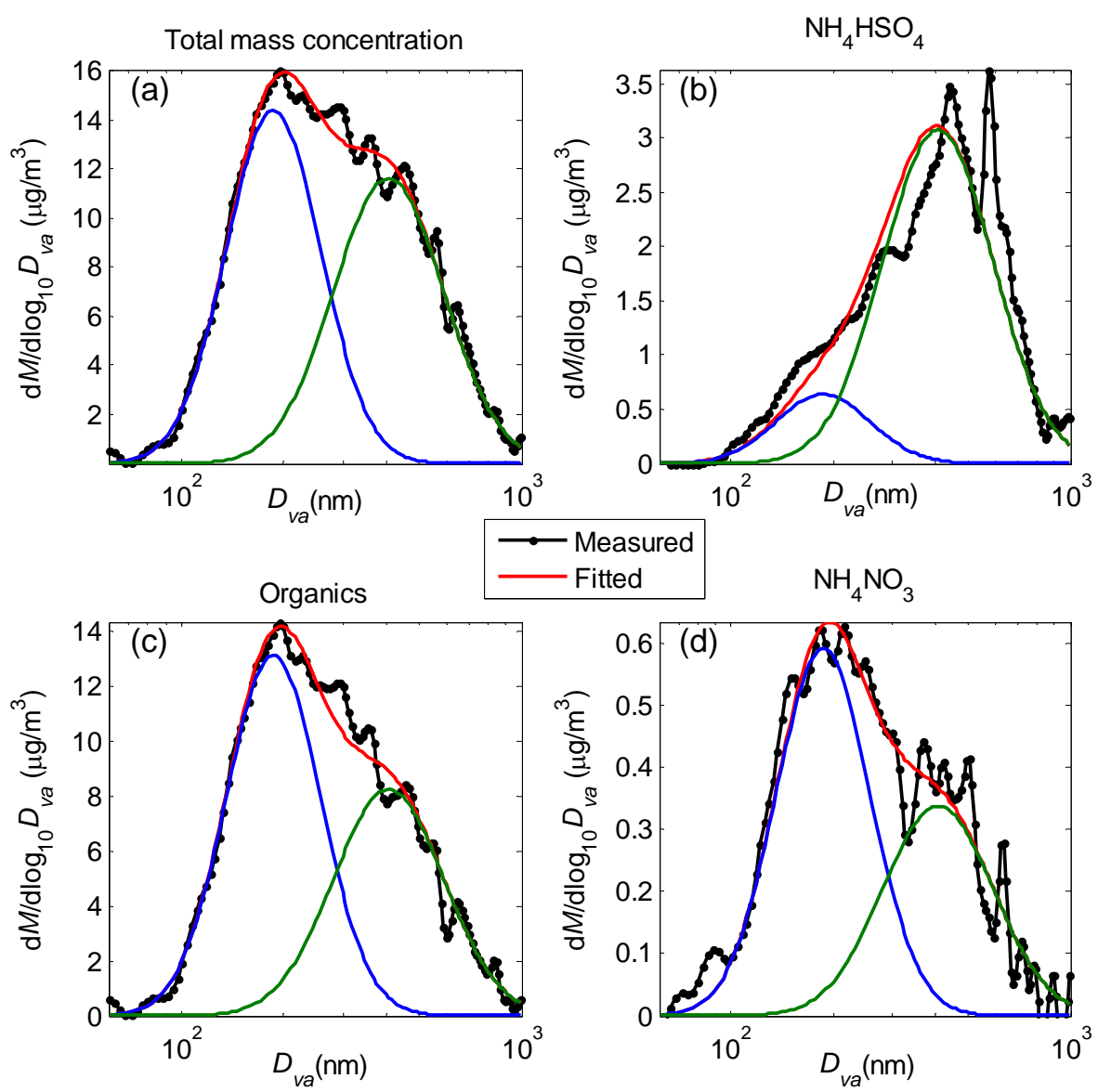

Fig. 5. Measured and fitted mass size distributions of total mass, $\mathrm{NH}_{4} \mathrm{HSO}_{4}$, organics, and $\mathrm{NH}_{4} \mathrm{NO}_{3}$ for the aerosol observed in a thin layer above cloud on $7 / 27 / 2005$. The black and red lines represent the measured and fitted total mass size distributions. The blue and green curves are fitted mass size distributions for each lognormal mode.

size distributions of total mass, $\mathrm{NH}_{4} \mathrm{HSO}_{4}, \mathrm{NH}_{4} \mathrm{NO}_{3}$ and organics agree closely with the measurements, supporting the assumption of an external mixture of internally mixed modes for the AC aerosols.

For each mode, the volume fractions were calculated from fitted mass fraction using the densities of participating species. For organics, a density of $1.2 \mathrm{~g} / \mathrm{cm}^{3}$ is used in this study. For the AC aerosols observed on 27 July 2005, the fitted lognormal mode parameters and the volume fraction of each species are listed in Table 1 . The vacuum aerodynamic diameters $\left(D_{v a}\right)$ of the two modes were $190 \mathrm{~nm}$ and $410 \mathrm{~nm}$, respectively. The smaller mode was dominated by organics, which contributed over $90 \%$ of the total volume. For the larger mode, the sulfate volume fraction was about $20 \%$, a substantial increase from the fraction in the smaller mode. The fitting procedure described above was carried out for the $\mathrm{AC}$ aerosols observed on all flights.
4.3 $\mathrm{CCN}$ closure study and the sensitivity of predicted $N_{\mathrm{CCN}}$ to the properties of organic species

\subsubsection{CCN Closure study with assumption of insoluble or- ganics}

Closure studies were carried out for $N_{\mathrm{CCN}}$ at $\sim 0.2 \%$ supersaturation using the following approach. For the FT and $\mathrm{BL}$ aerosols, which were treated as complete internal mixtures of sulfate, nitrate, and organics, the fraction of each species was assumed independent of particle size and was derived from the AMS MS-mode measurements averaged over the SMPS measurement intervals. We point out that due to the lower time resolution of SMPS, size distributions during which substantial variation in $N_{\mathrm{CCN}}$ was observed were excluded. Based on the derived composition, the critical dry particle activation diameter $\left(D_{p c}\right)$ was calculated using the $\kappa$-Köhler theory for each SMPS measurement interval, and $N_{\mathrm{CCN}}$ was then derived by integrating the size distribution from $D_{p c}$ and above. The AC aerosols were considered as external mixtures of internally mixed lognormal modes. As 
Table 1. The fitted lognormal mode parameters and volume fraction of $\mathrm{NH}_{4} \mathrm{HSO}_{4}$, organics, and $\mathrm{NH}_{4} \mathrm{NO}_{3}$ for the aerosol observed in a thin layer above cloud on 7/27/2005.

\begin{tabular}{ccccccc}
\hline Mode & $\begin{array}{c}D_{v a} \\
(\mathrm{~nm})\end{array}$ & $\begin{array}{c}M \\
\left(\mu \mathrm{g} / \mathrm{m}^{3}\right)\end{array}$ & $\sigma$ & $\begin{array}{c}\text { Vol. fraction } \\
\left(\mathrm{NH}_{4} \mathrm{HSO}_{4}\right)\end{array}$ & $\begin{array}{c}\text { Vol. fraction } \\
\left(\mathrm{NH}_{4} \mathrm{NO}_{3}\right)\end{array}$ & $\begin{array}{c}\text { Vol. fraction } \\
(\text { Organics })\end{array}$ \\
\hline 1 & 190 & 5.0 & 1.38 & $3.0 \%$ & $3.0 \%$ & $94 \%$ \\
2 & 410 & 4.7 & 1.45 & $20 \%$ & $2.0 \%$ & $78 \%$ \\
\hline
\end{tabular}
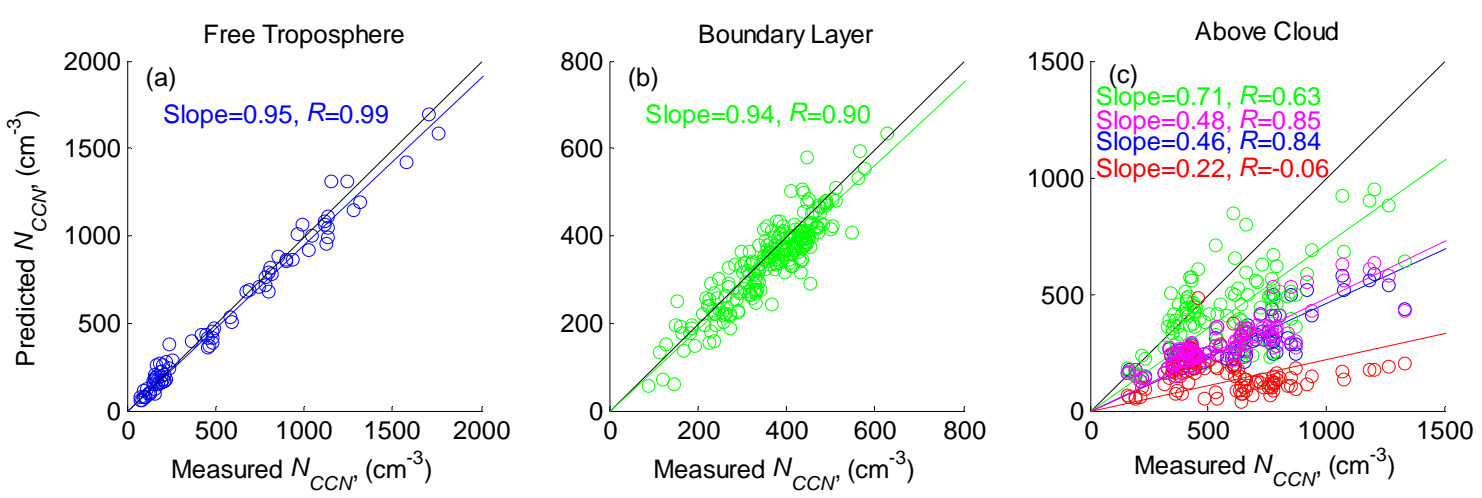

Fig. 6. Comparison of predicted and measured $N_{\mathrm{CCN}}$ at $\sim 0.2 \%$ for (a) Free Troposphere, (b) Boundary layer, and (c) Above Cloud aerosols. For the Free Troposphere and Boundary layer aerosols, $N_{\mathrm{CCN}}$ is predicted assuming a complete internal mixture with constant composition. For the Above Cloud aerosol, $N_{\mathrm{CCN}}$ is predicted assuming (1) a complete internal mixture with constant composition (green), (2) an internal mixture with size-dependent composition (magenta), (3) an external mixture of internally-mixed modes (blue), and (4) a complete external mixture with constant composition (red).

described in Sect. 4.2, the lognormal mode parameters and the composition of each mode were derived by fitting the size distributions of total mass and each species averaged over the layer. For each mode, the $N_{\mathrm{CCN}}$ was predicted using the same method described above, and the total $N_{\mathrm{CCN}}$ is the sum of the contribution from all modes. To examine the effects of mixing state on predicted $N_{\mathrm{CCN}}$, the $N_{\mathrm{CCN}}$ of the AC aerosol was also predicted assuming an internal mixture with size-dependent composition (i.e., at each size, particles have the same composition, and the composition varies with size as shown from the AMS data), a complete internal mixture with constant composition (i.e., all particles have the same average composition across the entire sub-micrometer size range, same as the FT and BL aerosols), and a complete external mixture with constant composition (i.e., all species are externally mixed at all sizes. The composition is constant across the entire sub-micrometer size range, and was derived from the AMS MS mode data).

As a starting point, the organic species were assumed to be water insoluble (i.e. $\kappa=0$ ), as in many previous closure studies. Figure 6 shows the comparison of predicted $N_{\mathrm{CCN}}$ to the measured at $\sim 0.2 \%$ supersaturation for all research flights. When the organic species are assumed to be insoluble, the predicted $N_{\mathrm{CCN}}$ for the FT and BL aerosols agrees well with the measured $N_{\mathrm{CCN}}$. The ratio of predicted to mea- sured $N_{\mathrm{CCN}}$, (i.e. the slope of the best fit) is 0.95 and 0.94 for the FT and BL aerosols, respectively. For the AC aerosols, the ratio is substantially less than unity regardless of the assumed mixing state, suggesting that assuming insoluble organics significantly underestimates the $N_{\mathrm{CCN}}$. The ratio is the lowest, 0.22 , when assuming a complete external mixture with constant composition, and is the highest, 0.71 , with the assumption of a complete internal mixture. The ratios are almost identical, 0.46 and 0.48 , when the $\mathrm{AC}$ aerosol is assumed as an external mixture of internally mixed modes and an internal mixture with size-dependent composition, respectively. The large differences among different assumptions suggest that predicted $N_{\mathrm{CCN}}$ strongly depends on the aerosol mixing state when organics are insoluble, in agreement with previous studies (e.g. Cubison et al., 2007). It is expected that the $\mathrm{AC}$ aerosol was most likely an external mixtures of internally mixed modes or an internal mixture with size-dependent composition. A complete internal mixture is inconsistent with the size-dependent composition observed by the AMS, and a complete external mixture is deemed unlikely for the aged AC aerosol. The extreme scenarios of a complete internal mixture and a complete external mixture serve as the limiting cases in our analysis.

As described earlier, sulfate was assumed to exist as $\mathrm{NH}_{4} \mathrm{HSO}_{4}$. To examine the uncertainty associated with this 
assumption, we also carried out a closure study treating all sulfate as completely neutralized $\left(\mathrm{NH}_{4}\right)_{2} \mathrm{SO}_{4}$. The results are very similar; the ratios are $0.93,0.91$, and 0.46 for the FT, BL, and AC aerosols, respectively. The sensitivity of predicted $N_{\mathrm{CCN}}$ to particle composition was also investigated by varying the mass concentration of sulfate. When the sulfate mass concentration is increased by $20 \%$, the ratio only increases slightly to 0.99 and 0.97 for the FT and BL aerosols, respectively. Similarly, both ratios decrease slightly to 0.90 for the FT and BL aerosols when the mass loading of sulfate is decreased by $20 \%$. As the assumption that the chemical composition was independent of particle size may not be appropriate for all FT and BL aerosols, the good agreement may be partially due to the low sensitivity of predicted $N_{\mathrm{CCN}}$ to the chemical composition for these two types of aerosols.

\subsubsection{Sensitivity of predicted $N_{\mathrm{CCN}}$ to the $\kappa$ value of or- ganic species}

Many organic species observed in the atmosphere are water soluble and have $\kappa$ values greater than zero. It is worth pointing out that some water-soluble organics may exhibit a $\kappa$ value of zero. The reason for this apparent contradiction is that the analytical methods used to extract water-soluble organics from particulates (e.g. Particle-Into-Liquid-Sampler) operates at very high dilution, whereas the water to solute mass ratio at particle activation may not be sufficient high to substantially dissolve the organics (Ervens et al., 2007). Petters and Kreidenweis (2007) showed that $\kappa$ values for organic species commonly observed in the atmosphere range mostly from 0 to 0.25 . The sensitivity of predicted $N_{\mathrm{CCN}}$ to the $\kappa$ value of organic species $\left(\kappa_{\text {org }}\right)$ is investigated in this section. For each of the three aerosol types defined above, $N_{\mathrm{CCN}}$ was predicted using a wide range of $\kappa_{\text {org }}$; the ratio of predicted to measured $N_{\mathrm{CCN}}$ is shown in Fig. 7 as a function of $\kappa_{\mathrm{org}}$. For the FT and BL aerosols, the predicted $N_{\mathrm{CCN}}$ is insensitive to $\kappa_{\text {org }}$. When $\kappa_{\text {org }}$ increases from 0 to 0.25 , the ratio of predicted to measured $N_{\mathrm{CCN}}$ increases only slightly from 0.95 to 1.15 for the FT aerosols, and from 0.94 to 1.10 for the $\mathrm{BL}$ aerosols. In contrast, the ratio increases from 0.46 to 1.50 for the $\mathrm{AC}$ aerosols when assuming an external mixture of internally mixed modes. The difference in the sensitivity to $\kappa_{\text {org }}$ is due to the following reason. Whereas organics contributed up to $50 \%$ of the aerosol volume for the FT and BL aerosols, the solute concentrations were dominated by the inorganics due to the high solubility of sulfate and nitrate (i.e. high $\kappa$ values). The additional contribution from soluble organics, which has relatively low $\kappa_{\text {org }}$, was only secondary. Therefore, the overall $\kappa$, a volume-weighted average for all species, is insensitive to $\kappa_{\text {org }}$. As a result, for a wide range of $\kappa_{\text {org }}$, the variations in the predicted $N_{\mathrm{CCN}}$ and the ratio of predicted to measured $N_{\mathrm{CCN}}$ are small for the FT and $\mathrm{BL}$ aerosols. For the $\mathrm{AC}$ aerosols, organics dominated the composition (i.e. up to $90 \%$ of the total aerosol volume concentration), and the ratio is highly sensitive to $\kappa_{\text {org }}$. The $\kappa_{\text {org }}$

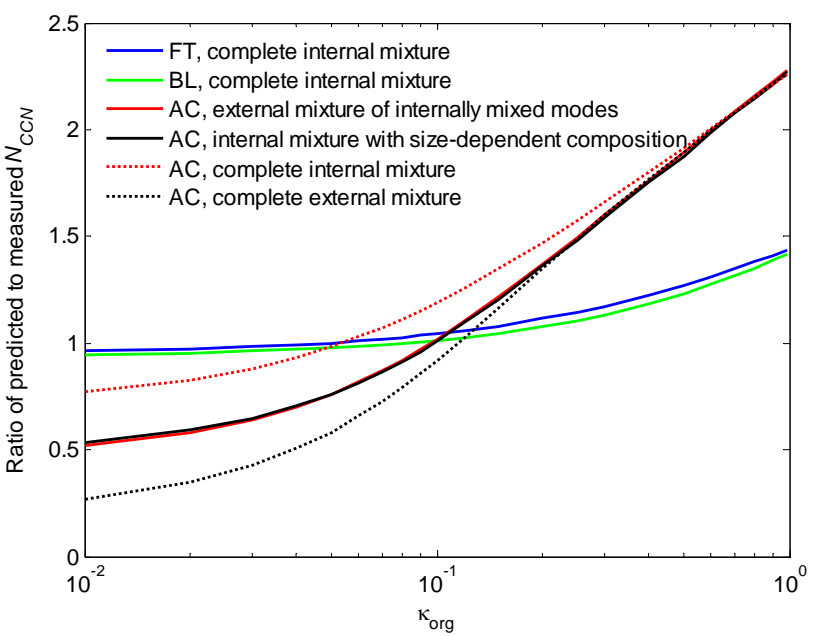

Fig. 7. The ratio of predicted to measured $N_{\mathrm{CCN}}$ as a function of $\kappa$ of organic species.

for the $\mathrm{AC}$ aerosols was derived as 0.1 by matching the predicted $N_{\mathrm{CCN}}$ to the measured. For the FT and BL aerosols, the low sensitivity of predicted $N_{\mathrm{CCN}}$ to $\kappa_{\text {org }}$ is an important reason for the good agreement between predicted and measured $N_{\mathrm{CCN}}$ even when the organics are assumed to be completely insoluble, which may not be true for many organic species observed away from the source regions.

To examine the effects of mixing state on predicted $N_{\mathrm{CCN}}$, we also calculated the variation in the ratio of predicted to measured $N_{\mathrm{CCN}}$ assuming an internal mixture with sizedependent composition, a complete internal mixture, and a complete external mixture described above. It is worth noting that assuming an internal mixture with size-dependent composition results in almost the same ratio as that based on an external mixture of internally mixed modes over the entire range of $\kappa_{\mathrm{org}}$. Regardless of the assumed aerosol mixing state, the ratio is highly sensitive to $\kappa_{\text {org }}$, a result of high organics volume fraction in the $\mathrm{AC}$ aerosol. At low $\kappa_{\text {org }}$ values, the predicted $N_{\mathrm{CCN}}$ strongly depends on the aerosol mixing state. The effect of aerosol mixing state on predicted $N_{\mathrm{CCN}}$ gradually decreases with increasing $\kappa_{\text {org }}$. As expected, at $\kappa_{\text {org }}$ similar to $\kappa$ value of sulfate, the predicted $N_{\mathrm{CCN}}$ becomes independent of the aerosol mixing state. The $\kappa_{\text {org }}$ for the $\mathrm{AC}$ aerosol is derived as 0.1 , similar to $\kappa$ of dicarboxylic acids and some SOA (Petters and Kreidenweis, 2007). At $\kappa_{\text {org }}$ of 0.1 , the ratio, based on a complete internal mixture with constant composition is 1.17 for the $\mathrm{AC}$ aerosol, and is 0.89 when a complete external mixture with constant composition is assumed. This corresponds to an uncertainly range of $-11 \%$ to $17 \%$ in predicted $N_{\mathrm{CCN}}$ due to the uncertainty in aerosol mixing state, which is substantially smaller than that at $\kappa_{\mathrm{org}}=0$. It is worth pointing out that a complete external mixture is very unlikely for atmospheric aerosols except for those observed very close to their sources. We expect 
the mixing state of most ambient aerosols is somewhere between a complete internal mixture and an external mixture of internally mixed modes described above.

\subsection{Uncertainty in first indirect aerosol effect}

4.4.1 Uncertainty in first indirect aerosol effect due to the uncertainty in $\kappa_{\text {org }}$

As discussed above, ambient aerosols often consist of hundreds of organic species, which cannot be speciated with current techniques or simulated in global models. The lack of knowledge of the organic properties will also lead to an uncertainty in predicted $N_{\mathrm{CCN}}$, as indicated in Fig. 7. The uncertainty in $N_{\mathrm{CCN}}$ translates into uncertainties in cloud droplet number concentration and albedo, and ultimately to the uncertainty in indirect aerosol effects. The uncertainty in average first indirect aerosol effect, $\Delta F_{c}$, can be estimated by (Schwartz and Slingo, 1996):

$\Delta F_{c} \approx-\frac{F_{T}}{4} A_{m s t} T_{r}^{2} \Delta R_{c}$

where $F_{T}$ is the solar constant, $A_{m s t}$ the cloud fractional coverage, and $T_{r}$ the fractional transmission of shortwave radiation above the cloud layer, and $\Delta R_{c}$ the uncertainty in cloud albedo. For global mean calculations, the cloud fraction is taken with the assumption (Charlson et al., 1987) that nonoverlapped marine stratus and stratocumulus clouds having a fractional area of $30 \%$, and $T_{r}$ is $76 \%$ (Schwartz and Slingo, 1996). For the range of cloud albedo $0.28 \leq R_{c} \leq 0.72$, which is characteristic of the prevalent and climatically important marine stratus clouds, $\Delta R_{c}$ can be estimated using the following equation with error less than $10 \%$ (Schwartz and Slingo, 1996; Wang, 2007):

$\Delta R_{c}=\frac{1}{3}\left[R_{c}\left(1-R_{c}\right)\right] \cdot \Delta \ln N_{d} \approx 0.075 \cdot \Delta \ln N_{d}$

where $N_{d}$ is the cloud droplet number concentration. Sotiropoulou et al. (2006) studied the uncertainty in $N_{d}$ associated with the uncertainty in $N_{\mathrm{CCN}}$ using field data and found that for majority of the cases, the relative uncertainty in $N_{d}$ is less than $50 \%$ of the relative uncertainty in $N_{\mathrm{CCN}}$. Therefore, the upper limit of the relative uncertainty of $N_{d}$ can be estimated as:

$\Delta \ln N_{d} \approx 0.5 \Delta \ln N_{\mathrm{CCN}}$

The lower relative uncertainty in $N_{d}$ is due to the feedback of the maximum supersaturation inside clouds. For example, at a constant updraft velocity, an increase in $N_{\mathrm{CCN}}$ leads to reduced maximum supersaturation inside the cloud due to the competition of water vapor among more particles. As a result, the fractional increase in $N_{d}$ will be less than that of $N_{\text {CCN }}$. Combining Eqs. (4), (5), and (6), we can estimate the upper limit of $\Delta F_{c}$ from the uncertainty in $N_{\mathrm{CCN}}$ as:

$\Delta F_{c} \approx-\frac{F_{T}}{4} A_{m s t} T_{r}^{2}\left(0.038 \Delta \ln N_{\mathrm{CCN}}\right) \approx-2.2 \cdot \Delta \ln N_{\mathrm{CCN}}\left(\mathrm{W} / \mathrm{m}^{2}\right)$
It is important to point out that Eq. (7) represents the upper limit of $\Delta F_{c}$, the true uncertainty in the first indirect aerosol effect could be substantially less. A recent study based on GCM model (Sotiropoulou et al., 2007) found that a 9\% global average uncertainty in $N_{\mathrm{CCN}}$ leads to an uncertainty of $0.1 \mathrm{~W} / \mathrm{m}^{2}$ in global average first indirect aerosol effect, only $50 \%$ of $0.2 \mathrm{~W} / \mathrm{m}^{2}$ predicted using Eq. (7).

The uncertainty in first indirect aerosol effect was estimated using Eq. (7) for the three types of aerosols observed during MASE. For the FT and BL aerosols, the predicted $N_{\mathrm{CCN}}$ is insensitive to $\kappa_{\text {org }}$ (Fig. 7). For the typical range of $\kappa_{\text {org }}$ from 0 to 0.25 , the uncertainties in predicted $\ln N_{\mathrm{CCN}}$ (i.e. $\left.\Delta \ln N_{\mathrm{CCN}}\right)$ are 0.18 and 0.16 , which correspond to $\Delta F_{c}$ of 0.40 and $0.35 \mathrm{~W} / \mathrm{m}^{2}$ for the FT and BL aerosols, respectively. For the AC aerosols, the high sensitivity of $N_{\mathrm{CCN}}$ to $\kappa_{\text {org }}$ leads to a $\Delta F_{c}$ of $2.6 \mathrm{~W} / \mathrm{m}^{2}$ for $\kappa_{\text {org }}$ ranging from 0 to 0.25 . It is expected that ambient aerosols have a wide range of sensitivities of $\ln N_{\mathrm{CCN}}$ to $\kappa_{\mathrm{org}}$. The global average $\Delta F_{c}$ is based on the average $\Delta \ln N_{\mathrm{CCN}}$, and is likely somewhere between the cases examined here.

4.4.2 Uncertainties of predicted $N_{\mathrm{CCN}}$ and first indirect aerosol effect when assuming a constant $\kappa_{\text {org }}$

Given the complexity of organic species in ambient aerosol, a simplified description of organic species is necessary to predict aerosol indirect effects using physically-based parameterizations in global models. In this section, we estimate the uncertainties in predicted $N_{\mathrm{CCN}}$ and first indirect aerosol effect for a simplified representation, in which a constant $\kappa$ value, $\overline{\kappa_{\text {org }}}=0.12$, is used to represent all organic species. We note that $\overline{\kappa_{\text {org }}}$ fall in the middle of the typical $\kappa_{\text {org }}$ range of 0 to 0.25 for ambient organics. To simplify our analysis, we start with internally mixed aerosols and represent all inorganic species using $\mathrm{NH}_{4} \mathrm{HSO}_{4}$. As the $\kappa$ values of other common inorganic species (e.g. $\left(\mathrm{NH}_{4}\right)_{2} \mathrm{SO}_{4}$ and $\mathrm{NH}_{4} \mathrm{NO}_{3}$ ) are very close to the $\kappa$ of $\mathrm{NH}_{4} \mathrm{HSO}_{4}$, we do not expect this assumption will affect the conclusion of our analysis. For internally mixed aerosols such as the FT and BL aerosols observed during MASE, $N_{\mathrm{CCN}}$ can be calculated as:

$N_{\mathrm{CCN}}=\int_{\ln D_{p c}}^{+\infty} n\left(\ln D_{p}\right) d \ln D_{p}$,

where $n\left(\ln D_{p}\right)$ is particle size distribution, $D_{p c}$ the critical dry activation diameter. The sensitivity of predicted $N_{\mathrm{CCN}}$ to the overall $\kappa$ of particle is given by:

$\frac{d \ln N_{\mathrm{CCN}}}{d \ln \kappa}=\frac{d \ln N_{\mathrm{CCN}}}{d \ln D_{p c}} \cdot \frac{d \ln D_{p c}}{d \ln \kappa}$.

Based on Eq. (8), the sensitivity of $N_{\mathrm{CCN}}$ to $D_{p c}$ is given by:

$\frac{d \ln N_{\mathrm{CCN}}}{d \ln D_{p c}}=\frac{1}{N_{\mathrm{CCN}}} \frac{d N_{\mathrm{CCN}}}{d \ln D_{p c}}=-\frac{n\left(\ln D_{p c}\right)}{N_{\mathrm{CCN}}}$ 
For $\kappa>0.2$, which is typical for atmospheric particles, we have (Petters and Kreidenweis, 2007):

$\kappa=\frac{4\left(\frac{4 \sigma_{w} M_{w}}{R T \rho_{w}}\right)^{3}}{27 D_{p c}^{3} \ln ^{2} S_{c}}$,

where $S_{c}$ is the critical supersaturation. From Eq. (11), the following equation can be derived:

$\frac{d \ln D_{p c}}{d \ln \kappa}=-\frac{1}{3}$

Combining Eqs. (9), (10), and (12), we can derive the sensitivity of $N_{\mathrm{CCN}}$ to overall $\kappa$ as:

$\frac{d \ln N_{\mathrm{CCN}}}{d \ln \kappa}=\frac{1}{3} \frac{n\left(\ln D_{p c}\right)}{N_{\mathrm{CCN}}}$

When all organic species are represented using $\overline{\kappa_{\text {org }}}$, the fraction error in calculate $N_{\mathrm{CCN}}$ can be estimated using Eq. (13):

$$
\begin{aligned}
& \frac{\Delta N_{\mathrm{CCN}}}{N_{\mathrm{CCN}}} \approx \Delta \ln N_{\mathrm{CCN}}=\ln \left(\frac{N_{\mathrm{CCN}}^{\prime}}{N_{\mathrm{CCN}}}\right) \\
& \quad=\frac{1}{3} \frac{n\left(\ln D_{p c}\right)}{N_{\mathrm{CCN}}} \ln \left(\frac{\left(1-x_{\mathrm{org}}\right) \kappa_{\mathrm{ABS}}+x_{\mathrm{org}} \overline{\kappa_{\mathrm{org}}}}{\left(1-x_{\mathrm{org}}\right) \kappa_{\mathrm{ABS}}+x_{\mathrm{org}} \kappa_{\mathrm{org}}}\right)
\end{aligned}
$$

where $N_{\mathrm{CCN}}^{\prime}$ is the $\mathrm{CCN}$ concentration predicted using the $\overline{\kappa_{\text {org }}}(0.12), \kappa_{\mathrm{ABS}}$ the $\kappa$ of ammonium bisulfate $(0.7)$, and $x_{\text {org }}$ the volume fraction of organic species. For aerosols with composition (i.e. $x_{\text {org }}$ ) varying with particle size, $x_{\text {org }}$ represents the volume fraction of organics at $D_{p c}$.

For externally mixed aerosols, the total $N_{\mathrm{CCN}}$ is the sum of $N_{\mathrm{CCN}}$ of each participating population:

$N_{\mathrm{CCN}}=\sum_{j} N_{\mathrm{CCN}, j}$

where $N_{\mathrm{CCN}, j}$ represents the $\mathrm{CCN}$ concentration of each aerosol population. The fractional error of the total $N_{\mathrm{CCN}}$ is then given by:

$$
\frac{\Delta N_{\mathrm{CCN}}}{N_{\mathrm{CCN}}}=\sum_{j} \frac{\Delta N_{\mathrm{CCN}, j}}{N_{\mathrm{CCN}}}=\sum_{j}\left(\frac{N_{\mathrm{CCN}, j}}{N_{\mathrm{CCN}}}\right) \frac{\Delta N_{\mathrm{CCN}, j}}{N_{\mathrm{CCN}, j}}
$$

Equation (16) shows that for externally mixed aerosols, the fractional error in overall $N_{\mathrm{CCN}}$ will be a weighted average of the fractional error for each aerosol population. For example, the fractional error in $N_{\mathrm{CCN}}$ of the AC aerosol will be the weighted average of the fraction error for each internally mixed mode. In the rest of this section, we examine internally mixed aerosols. According to Eq. (14), for $\kappa_{\text {org ranging }}$ from 0 to 0.25 , the maximum fractional error in $N_{\mathrm{CCN}}$ for using $\overline{\kappa_{\text {org }}}$ occurs when $\kappa_{\text {org }}$ is either 0 or 0.25 . The corresponding error on the aerosol first indirect effect, $\Delta F_{c}$, can be derived by combining Eqs. (7) and (14):

$$
\begin{aligned}
\Delta F_{c} & \approx-2.2 \cdot \Delta \ln N_{\mathrm{CCN}} \\
& =-0.7 \frac{n\left(\ln D_{p c}\right)}{N_{\mathrm{CCN}}} \ln \left(\frac{0.70\left(1-x_{\mathrm{org}}\right)+0.12 x_{\mathrm{org}}}{0.70\left(1-x_{\mathrm{org}}\right)+\kappa_{\mathrm{org}} x_{\mathrm{org}}}\right)
\end{aligned}
$$

The value of $\frac{n\left(\ln D_{p c}\right)}{N_{C C N}}$ depends on the shape of particle size distribution and $D_{p c}$, and is generally high near the peak diameter of the number size distribution $n\left(\ln D_{p}\right)$. In addition, $\frac{n\left(\ln D_{p c}\right)}{N_{\mathrm{CCN}}}$ also varies with supersaturation, which determines $D_{p c}$. The value of $\frac{n\left(\ln D_{p c}\right)}{N_{\mathrm{CCN}}}$ is often lower at higher supersaturation, which corresponds to a higher denominator $N_{\mathrm{CCN}}$. This might be one of the reasons that better closure agreements were often achieved at higher supersaturations. The average $\frac{n\left(\ln D_{p c}\right)}{N_{\mathrm{CCN}}}$ is 1.60 and 1.35 for the FT and $\mathrm{BL}$ aerosols, respectively. For typical marine, rural, urban, and remote continental aerosol (Seinfeld and Pandis, 2006) $\frac{n\left(\ln D_{p c}\right)}{N_{\mathrm{CCN}}}$ ranges from 0.2 to 2.3 for $D_{p c}$ between 50 and $150 \mathrm{~nm}$, which is the typical range of $D_{p c}$ under climatically relevant supersaturations. For an average $\frac{n\left(\ln D_{p c}\right)}{N_{\mathrm{CCN}}}$ of 1.3, $\Delta F_{c}$ is calculated as a function of $x_{\text {org }}$ and $\kappa_{\text {org }}$ using Eq. (17) and the results are shown in Fig. 8. As expected, $\Delta F_{c}$ increases with increasing $x_{\text {org }}$ (Fig. 8a). When organic volume fraction was lower than $\sim 60 \%$, using $\overline{\kappa_{\text {org }}}$ for all organic species leads to $\Delta F_{c}$ of less than $0.2 \mathrm{~W} / \mathrm{m}^{2}$ for typical $\kappa_{\mathrm{org}}$ ranging from 0 to 0.25 . However, since Eq. (17) is based on Eq. (6), which assumes the upper limit of the uncertainty in $N_{d}, \Delta F_{c}$ can be as low as $50 \%$ (i.e. $0.1 \mathrm{~W} / \mathrm{m}^{2}$ ) of the estimate using Eq. (17) (Sotiropoulou et al., 2007). Furthermore, it is expected that ambient organics will have a wide range of $\kappa_{\mathrm{org}}$ distributed about the central value of 0.12 . As a result, when averaged over a large area and/or extended time period, $\Delta F_{c}$ may be substantially less than the $0.2 \mathrm{~W} / \mathrm{m}^{2}$ limit shown in Fig. 8a. However, if organics dominate the aerosol volume, $\Delta F_{c}$ becomes significant: when organics contribute to $\sim 90 \%$ of the total aerosol volume, $\Delta F_{c}$ is -1.0 and $0.6 \mathrm{~W} / \mathrm{m}^{2}$ at $\kappa_{\mathrm{org}}$ of 0 and 0.25 , respectively. The $\Delta F_{c}$ is less than $0.2 \mathrm{~W} / \mathrm{m}^{2}$ only for $\kappa_{\text {org }}$ within a narrow range from 0.09 and 0.16 . This suggests that when organics dominates the aerosol volume, the accurate knowledge of the overall $\kappa_{\text {org }}$ (i.e., the volume weighted $\kappa$ for all organics) is required to accurately predict $N_{\mathrm{CCN}}$ and first indirect aerosol effect.

Based on previous field measurements, the $\frac{n\left(\ln D_{p c}\right)}{N_{\mathrm{CCN}}}$ of marine aerosols ranges from 0.2 to 1.5 for $D_{p c}$ between 50 and $150 \mathrm{~nm}$ (Quinn et al., 1995; Van Dingenen et al., 1995; Jensen et al., 1996; Seinfeld and Pandis, 2006). Unlike urban and continental aerosols whose number concentrations are often dominated by small nucleation mode and/or Aitken mode particles, marine aerosols often consist of a larger fraction of accumulation mode particles (Seinfeld and Pandis, 2006). As accumulation mode particles are likely to be CCN due to their large size, marine aerosols often have larger percentage of total particles that are $\mathrm{CCN}$, which preferentially increases the denominator of Eq. (10). As a result, marine aerosols tend to have relatively lower values of $\frac{n\left(\ln D_{p c}\right)}{N_{\mathrm{CCN}}}$. Figure $8 \mathrm{~b}$ shows the $\Delta F_{c}$ calculated using an average $\frac{n\left(\ln D_{p c}\right)}{N_{\mathrm{CCN}}}$ of 0.9 for marine aerosols. For $\kappa_{\text {org }}$ ranging from 0 to 0.25 , using $\overline{\kappa_{\text {org }}}=0.12$ for all organic species results in a $\Delta F_{c}$ less 

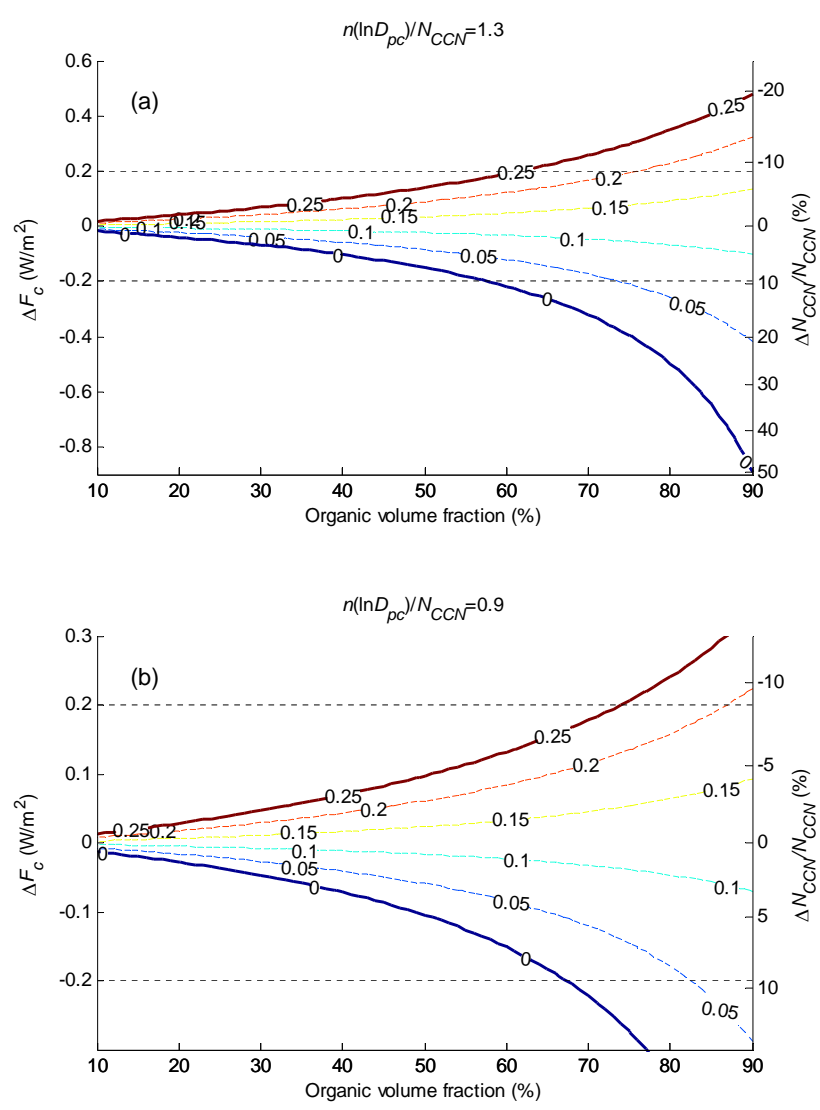

Fig. 8. Estimated uncertainties in the first indirect aerosol effect $\left(\Delta F_{c}\right)$ and predicted $N_{\mathrm{CCN}}\left(\Delta N_{\mathrm{CCN}} / N_{\mathrm{CCN}}\right)$ when using a constant $\overline{\kappa_{\text {org }}}$ of 0.12 for all organic species in an internal mixture. $\Delta F_{C}$ is related to $\Delta N_{\mathrm{CCN}} / N_{\mathrm{CCN}}$ using Eq. (17). The uncertainties are plotted as functions of $x_{\text {org }}$ (i.e., volume fraction of organics at $D_{p c}$ ) for (a) $n\left(\ln D_{p c}\right) / N_{\mathrm{CCN}}=1.3$ and (b) $n\left(\ln D_{p c}\right) / N_{\mathrm{CCN}}=0.9$ for marine aerosols. The curves are labeled with $\kappa_{\mathrm{org}}$.

than $0.2 \mathrm{~W} / \mathrm{m}^{2}$ when organic species contribute to less than $70 \%$ of the aerosol volume, which is likely true for most marine aerosols. Zhang et al. (2007) presented aerosol chemical composition measured by AMS over the Northern Hemisphere mid-latitudes, where the aerosols are influenced by anthropogenic emissions. The volume fraction of organics estimated from the data shows that among the 37 datasets presented, the volume fraction of organics is less than $60 \%$ for 26 datasets and less than $70 \%$ for 32 datasets. The less than $0.2 \mathrm{~W} / \mathrm{m}^{2} \Delta F_{c}$ corresponds to less than $10 \%$ uncertainty in predicted $N_{\mathrm{CCN}}$. The low uncertainty in the predicted $N_{\mathrm{CCN}}$ when organic species make up less than $60-70 \%$ of aerosol volume is consistent with the results from the closure study using MASE data described in earlier sections. This can also potentially explain the results of previous closure studies, which showed that better closure agreements were generally achieved when the aerosol contained low organic content.

\section{Summary}

For each of the three aerosol types observed during MASE, closure analysis was carried out by comparing the $N_{\mathrm{CCN}}$ predicted from the measured size distribution and chemical composition using $\kappa$-Köhler theory to simultaneously measured $N_{\mathrm{CCN}}$. For FT and BL aerosols, the predicted $N_{\mathrm{CCN}}$ is insensitive to the properties of organics. The predicted $N_{\mathrm{CCN}}$ shows little variation and agrees with the measured $N_{\mathrm{CCN}}$ to within $15 \%$ when $\kappa_{\text {org }}$ is assumed to be between 0 to 0.25 , which represents the typical range of $\kappa_{\text {org }}$ for ambient organic species. In contrast, $N_{\mathrm{CCN}}$ is a strong function of $\kappa_{\text {org }}$ for the AC aerosols. The predicted $N_{\mathrm{CCN}}$ is only $46 \%$ of the measured $N_{\mathrm{CCN}}$ if the organic species are assumed to be insoluble (i.e., $\kappa_{\text {org }}=0$ ), and $150 \%$ when $\kappa_{\text {org }}$ is assumed to be 0.25 . The $\kappa_{\text {org }}$ of the AC aerosols is consistent with a value of 0.1 derived by matching the predicted $N_{\mathrm{CCN}}$ to the measured. For the FT and BL aerosols, the low sensitivity of predicted $N_{\mathrm{CCN}}$ to $\kappa_{\mathrm{org}}$ arises because inorganic species, such as sulfate and nitrate, are more water soluble (i.e. higher $\kappa$ value) compared to typical organic species observed in the atmosphere. Whereas organic species contributed up to about half of the total aerosol volume for the FT and BL aerosols, the total soluble ions, which dictate particle $\mathrm{CCN}$ activity, were dominated by inorganic species, and the additional contribution from the organic species was only secondary. For the AC aerosols, organics contributed up to $90 \%$ of the total aerosol volume at $D_{p c}$. As a result, the predicted $N_{\mathrm{CCN}}$ is highly sensitive to $\kappa_{\text {org }}$.

Atmospheric aerosols often consist of hundreds of organic species, which cannot be simulated individually in global models due to computational constraints. The inability to simulate individual species, coupled with the lack of thermodynamic data of many organic compounds, necessitate simplified representations of organic species when using physically based parameterizations in large scale models to evaluate indirect aerosol effects. A simplified representation in which a constant $\overline{\kappa_{\text {org }}}$ of 0.12 is used for all organics is explored. The analysis shows that for typical aerosol size distribution, the predicted $N_{\mathrm{CCN}}$ and the corresponding first indirect aerosol effect are insensitive to the properties of organic species when the volume fraction of aerosol organics is less than $60 \%$. As a result, the estimated uncertainty in the first indirect aerosol effect $\left(\Delta F_{c}\right)$ for using $\overline{\kappa_{\text {org }}}(0.12)$ is low, between -0.2 and $0.2 \mathrm{~W} / \mathrm{m}^{2}$ for $\kappa_{\text {org }}$ between 0 and 0.25 , the typical range of $\kappa_{\text {org }}$ for ambient aerosols. It is worth noting that $0.2 \mathrm{~W} / \mathrm{m}^{2}$ represents the upper limit of the uncertainty. Since the ambient aerosol organic species are expected to have a wide range of $\kappa_{\text {org }}$ surrounding $0.12, \Delta F_{c}$ may be substantially less than $0.2 \mathrm{~W} / \mathrm{m}^{2}$ when averaged over large area and/or extended time period. As expected, $\Delta F_{c}$ due to the simplified treatment increases with increasing organics volume fraction. For example, when organics contribute to $90 \%$ of the total aerosol volume, the $\Delta F_{c}$ can reach 0.6 and $-1.0 \mathrm{~W} / \mathrm{m}^{2}$. Analyses show that $\Delta F_{c}$ associated with the 
simplification depends on not only the volume fraction of organic species but also the shape of the aerosol size distribution, which controls the sensitivity of the predicted $N_{\mathrm{CCN}}$ to $D_{p c}$. For marine aerosols that often consist of larger fractions of accumulation particles, the sensitivity of predicted $N_{\mathrm{CCN}}$ to $D_{p c}$ is low, which leads to lower sensitivity of predicted $N_{\mathrm{CCN}}$ to $\kappa_{\text {org }}$. Based on the marine aerosols measured during previous field studies, using $\overline{\kappa_{\text {org }}}$ for all organic species lead to $\Delta F_{c}$ less than $0.2 \mathrm{~W} / \mathrm{m}^{2}$ provided that the organic volume fraction is less than $70 \%$, which is likely to be true for most marine aerosols. Due to the extensive spatial coverage and high susceptibility of marine stratus/stratocumulus, the low uncertainties in predicted $N_{\mathrm{CCN}}$ and the first indirect aerosol effect for marine aerosols will contribute to low uncertainties in global averages. The low sensitivity of predicted $N_{\mathrm{CCN}}$ to $\kappa_{\text {org }}$ for aerosols with an organic volume fraction less than $60-70 \%$ can potentially explain the results of previous closure studies, which showed better agreements were generally achieved when the aerosol contained low organic content.

It is important to note that the analyses presented in this work are based on a number of assumptions. Nevertheless, they suggest that for many situations, first indirect aerosol effect can be predicted with sufficient accuracy using a constant $\overline{\kappa_{\text {org }}}$ of 0.12 for all organics present in the aerosol. This can significantly simplify the calculation of $N_{\mathrm{CCN}}$, and facilitate the prediction of indirect aerosol effects using physically-based parameterizations in global models. More field data and modeling studies will be needed to assess the distribution of organics in the atmosphere, and the spatial and temporal coverage of aerosols dominated by organics, as detailed knowledge of the organic properties is required to accurately predict $N_{\mathrm{CCN}}$ for these aerosols. Derivations of $\kappa_{\text {org }}$ in future closure studies, when aerosols are dominated by organic species, would help constrain the descriptions of organics and aerosol-cloud parameterizations in large scale models. We note that the uncertainties in first indirect aerosol effect estimated here represent upper limits, which could be a factor of 2 greater than the true values, as suggested by the results from Sotiropoulou et al. (2007). Nevertheless, the analyses here show that using $\overline{\kappa_{\text {org }}}$ for all organic species may be sufficient for many aerosol types. The accuracy of globally averaged aerosol indirect effects for using $\overline{\kappa_{\text {org }}}$ should be evaluated using global models, which will be a subject of our future studies. An efficient and accurate representation of organics may require a combination of the constant $\overline{\kappa_{\text {org }}}$ for most aerosol and $\kappa_{\text {org }}$ constrained by field studies for aerosols dominated by organics (i.e., organic volume fraction greater than $\sim 60-70 \%$ ).

Acknowledgements. The authors thank Steven Springston who reduced the aircraft data used in this analysis and Bob Hannigan, Chief Pilot of the DOE G-1 aircraft for outstanding performance. We also thank two anonymous reviewers and Ernie Lewis for their thoughtful and constructive comments. This work was supported by the US Department of Energy's Atmospheric Science Program (Office of Science, OBER) under contract DE-AC02-98CH10886.
Edited by: U. Lohmann

\section{References}

Abdul-Razzak, H. and Ghan, S. J.: A parameterization of aerosol activation 2. Multiple aerosol types, J. Geophys. Res., 105, 6837-6844, 2000.

Allan, J. D., Delia, A. E., Coe, H., Bower, K. N., Alfarra, M. R., Jimenez, J. L., Middlebrook, A. M., Drewnick, F., Onasch, T. B., Canagaratna, M. R., Jayne, J. T., and Worsnop, D. R.: A generalised method for the extraction of chemically resolved mass spectra from aerodyne aerosol mass spectrometer data, J. Aerosol Sci., 35, 909-922, 2004.

Bilde, M. and Svenningsson, B.: CCN activation of slightly soluble organics: the importance of small amounts of inorganic salt and particle phase, Tellus B, 56, 128-134, 2004.

Broekhuizen, K., Chang, R. Y.-W., Leaitch, W. R., Li, S.-M., and Abbatt, J. P. D.: Closure between measured and modeled cloud condensation nuclei $(\mathrm{CCN})$ using size-resolved aerosol compositions in downtown Toronto, Atmos. Chem. Phys., 6, 2513-2524, 2006, http://www.atmos-chem-phys.net/6/2513/2006/.

Cantrell, W., Shaw, G., Cass, G. R., Chowdhury, Z., Hughes, L. S., Prather, K. A., Guazzotti, S. A., and Coffee, K. R.: Closure between aerosol particles and cloud condensation nuclei at Kaashidhoo Climate Observatory, J. Geophys. Res., 106, 28711-28 718, 2001.

Chuang, P. Y., Collins, D. R., Pawlowska, H., Snider, J. R., Jonsson, H. H., Brenguier, J. L., Flagan, R. C., and Seinfeld, J. H.: CCN measurements during ACE-2 and their relationship to cloud microphysical properties, Tellus B, 52, 843-867, 2000.

Clegg, S. L., Brimblecombe, P., and Wexler, A. S.: Thermodynamic model of the system H+-NH4+-Na+-SO42-NB3-ClH2O at 298.15 K, J. Phys. Chem. A, 102, 2155-2171, 1998.

Cubison, M. J., Ervens, B., Feingold, G., Docherty, K. S., Ulbrich, I. M., Shields, L., Prather, K., Hering, S., and Jimenez, J. L.: The influence of chemical composition and mixing state of Los Angeles urban aerosol on $\mathrm{CCN}$ number and cloud properties, Atmos. Chem. Phys., 8, 5649-5667, 2008, http://www.atmos-chem-phys.net/8/5649/2008/.

Collins, D. R., Flagan, R. C., and Seinfeld, J. H.: Improved inversion of scanning DMA data, Aerosol Sci. Technol., 36, 1-9, 2002.

Daum, P. H., Liu, Y. G., McGraw, R. L., Lee, Y. N., Wang, J., Senum, G. I., Miller, M., and Hudson, J. G.: Microphysical properties of stratus/stratocumulus Clouds during the $2005 \mathrm{Ma}-$ rine Stratus/Stratocumulus Experiments (MASE), in preparation, 2008.

Ervens, B., Feingold, G., and Kreidenweis, S. M.: Influence of water-soluble organic carbon on cloud drop number concentration, J. Geophys. Res., 110, D18211, doi:10.1029/2004JD005634, 2005.

Ervens, B., Cubison, M., Andrews, E., Feingold, G., Ogren, J. A., Jimenez, J. L., DeCarlo, P., and Nenes, A.: Prediction of cloud condensation nucleus number concentration using measurements of aerosol size distributions and composition and light scattering enhancement due to humidity, J. Geophys. Res., 112, D10S32, doi:10.1029/2006JD007426, 2007. 
Facchini, M. C., Mircea, M., Fuzzi, S., and Charlson, R. J.: Cloud albedo enhancement by surface-active organic solutes in growing droplets, Nature, 401, 257-259, 1999.

Huff-Hartz, K. E. H., Tischuk, J. E., Chan, M. N., Chan, C. K., Donahue, N. M., and Pandis, S. N.: Cloud condensation nuclei activation of limited solubility organic aerosol, Atmos. Environ., 40, 605-617, 2006.

Intergovernmental panel on Climate Change (IPCC): Climate change 2007: The physical science basis, Cambridge University Press, New York, 2007.

Jayne, J. T., Leard, D. C., Zhang, X. F., Davidovits, P., Smith, K. A., Kolb, C. E., and Worsnop, D. R.: Development of an aerosol mass spectrometer for size and composition analysis of submicron particles, Aerosol Sci. Technol., 33, 49-70, 2000.

Jensen, T. L., Kreidenweis, S. M., Kim, Y., Sievering, H., and Pszenny, A.: Aerosol distributions in the North Atlantic marine boundary layer during Atlantic Stratocumulus Transition Experiment Marine Aerosol and Gas Exchange, J. Geophys. Res., 101, 4455-4467, 1996.

Kanakidou, M., Seinfeld, J. H., Pandis, S. N., Barnes, I., Dentener, F. J., Facchini, M. C., Van Dingenen, R., Ervens, B., Nenes, A., Nielsen, C. J., Swietlicki, E., Putaud, J. P., Balkanski, Y., Fuzzi, S., Horth, J., Moortgat, G. K., Winterhalter, R., Myhre, C. E. L., Tsigaridis, K., Vignati, E., Stephanou, E. G., and Wilson, J.: Organic aerosol and global climate modelling: a review, Atmos. Chem. Phys., 5, 1053-1123, 2005,

http://www.atmos-chem-phys.net/5/1053/2005/.

Kleinman, L. I., Daum, P. H., Lee, Y. N., Senum, G. I., Springston, S. R., Wang, J., Berkowitz, C., Hubbe, J., Zaveri, R. A., Brechtel, F. J., Jayne, J., Onasch, T. B., and Worsnop, D.: Aircraft observations of aerosol composition and ageing in New England and Mid-Atlantic States during the summer 2002 New England Air Quality Study field campaign, J. Geophys. Res., 112, D09310, doi:10.1029/2006JD007786, 2007.

Köhler, H.: The nucleus in and the growth of hygroscopic droplets, Trans. Farad. Soc., 32, 1152-1161, 1936.

Lewis, E. R. and Schwartz, S. E.: Sea Salt Aerosol Production: Mechanisms, Methods, Measurements, and Models, Geophysical Monograph Series, Vol. 152, American Geophysical Union, Washington, DC, 413 pp., 2004.

Liu, P. S. K., Leaitch, W. R., Banic, C. M., Li, S. M., Ngo, D., and Megaw, W. J.: Aerosol observations at Chebogue Point during the 1993 North Atlantic Regional Experiment: Relationships among cloud condensation nuclei, size distribution, and chemistry, J. Geophys. Res., 101, 28 971-28 990, 1996.

Medina, J., Nenes, A., Sotiropoulou, R. E. P., Cottrell, L. D., Ziemba, L. D., Beckman, P. J., and Griffin, R. J.: Cloud condensation nuclei closure during the International Consortium for Atmospheric Research on Transport and Transformation 2004 campaign: Effects of size-resolved composition, J. Geophys. Res., 112, D10S31, doi:10.1029/2006JD007588, 2007.

Menon, S., Del Genio, A. D., Koch, D., and Tselioudis, G.: GCM Simulations of the aerosol indirect effect: Sensitivity to cloud parameterization and aerosol burden, J. Atmos. Sci., 59, 692713, 2002.

Petters, M. D. and Kreidenweis, S. M.: A single parameter representation of hygroscopic growth and cloud condensation nucleus activity, Atmos. Chem. Phys., 7, 1961-1971, 2007, http://www.atmos-chem-phys.net/7/1961/2007/.
Quinn, P. K., Marshall, S. F., Bates, T. S., Covert, D. S., and Kapustin, V. N.: Comparison of measured and calculated aerosol properties relevant to the direct radiative forcing of tropospheric sulfate aerosol on climate, J. Geophys. Res., 100, 8977-8991, 1995.

Raymond, T. M. and Pandis, S. N.: Cloud activation of singlecomponent organic aerosol particles, J. Geophys. Res., 107, 4787, doi:10.1029/2002JD002159, 2002.

Raymond, T. M. and Pandis, S. N.: Formation of cloud droplets by multicomponent organic particles, J. Geophys. Res., 108, 4469, doi:10.1029/2003JD003503, 2003.

Rissman, T. A., VanReken, T. M., Wang, J., Gasparini, R., Collins, D. R., Jonsson, H. H., Brechtel, F. J., Flagan, R. C., and Seinfeld, J. H.: Characterization of ambient aerosol from measurements of cloud condensation nuclei during the 2003 Atmospheric Radiation Measurement Aerosol Intensive Observational Period at the Southern Great Plains site in Oklahoma, J. Geophys. Res., 111, D05S11, doi:10.1029/2004JD005695, 2006.

Roberts, G. C., Artaxo, P., Zhou, J. C., Swietlicki, E., and Andreae, M. O.: Sensitivity of CCN spectra on chemical and physical properties of aerosol: A case study from the Amazon Basin, J. Geophys. Res., 107, 8070, doi:10.1029/2001JD000583, 2002.

Roberts, G. C. and Nenes, A.: A continuous-flow streamwise thermal-gradient $\mathrm{CCN}$ chamber for atmospheric measurements, Aerosol Sci. Technol., 39, 206-221, 2005.

Rose, D., Gunthe, S. S., Mikhailov, E., Frank, G. P., Dusek, U., Andreae, M. O., and Pöschl, U.: Calibration and measurement uncertainties of a continuous-flow cloud condensation nuclei counter (DMT-CCNC): CCN activation of ammonium sulfate and sodium chloride aerosol particles in theory and experiment, Atmos. Chem. Phys., 8, 1153-1179, 2008, http://www.atmos-chem-phys.net/8/1153/2008/.

Schwartz, S. E. and Slingo, A.: Enhanced shortwave cloud radiative forcing due to anthropogenic aerosols., in: Clouds, Chemistry, and Climate., edited by: Crutzen, P., and Ramanathan, V., Springer, Heidelberg, 191-236, 1996.

Seinfeld, J. H. and Pandis, S. N.: Atmospheric Chemistry and Physics, 2nd Ed., John Wiley \& Sons, Inc., Hoboken, 2006.

Shulman, M. L., Jacobson, M. C., Carlson, R. J., Synovec, R. E., and Young, T. E.: Dissolution behavior and surface tension effects of organic compounds in nucleating cloud droplets, Geophys. Res. Lett., 23, 277-280, 1996.

Snider, J. R., Guibert, S., Brenguier, J. L., and Putaud, J. P.: Aerosol activation in marine stratocumulus clouds: 2. Köhler and parcel theory closure studies, J. Geophys. Res., 108, 8629, doi:10.1029/2002JD002692, 2003.

Sotiropoulou, R. E. P., Medina, J., and Nenes, A.: Ccn predictions: Is theory sufficient for assessments of the indirect effect?, Geophys. Res. Lett., 33, L05816, doi:10.1029/2005GL025148, 2006.

Sotiropoulou, R. E. P., Nenes, A., Adams, P. J., and Seinfeld, J. H.: Cloud condensation nuclei prediction error from application of Köhler theory: Importance for the aerosol indirect effect, J. Geophys. Res., 112, D12202, doi:10.1029/2006JD007834, 2007.

Stroud, C. A., Nenes, A., Jimenez, J. L., DeCarlo, P. F., Huffman, J. A., Bruintjes, R., Nemitz, E., Delia, A. E., Toohey, D. W., Guenther, A. B., and Nandi, S.: Cloud activating properties of aerosol observed during CELTIC, J. Atmos. Sci., 64, 441-459, 2007.

Svenningsson, B., Rissler, J., Swietlicki, E., Mircea, M., Bilde, M., 
Facchini, M. C., Decesari, S., Fuzzi, S., Zhou, J., Mønster, J., and Rosenørn, T.: Hygroscopic growth and critical supersaturations for mixed aerosol particles of inorganic and organic compounds of atmospheric relevance, Atmos. Chem. Phys., 6, 1937-1952, 2006 , http://www.atmos-chem-phys.net/6/1937/2006/.

Takemura, T., Nozawa, T., Emori, S., Nakajima, T. Y., and Nakajima, T.: Simulation of climate response to aerosol direct and indirect effects with aerosol transport-radiation model, J. Geophys. Res., 110, D02202, doi:10.1029/2004JD005029, 2005.

Twomey, S.: Influence of pollution on shortwave albedo of clouds, J. Atmos. Sci., 34, 1149-1152, 1977.

Vandingenen, R., Raes, F., and Jensen, N. R.: Evidence for anthropogenic impact on number concentration and sulfate content of cloud-processed aerosol-particles over the North-Atlantic, J. Geophys. Res., 100, 21 057-21 067, 1995.

VanReken, T. M., Rissman, T. A., Roberts, G. C., Varutbangkul, V., Jonsson, H. H., Flagan, R. C., and Seinfeld, J. H.: Toward aerosol/cloud condensation nuclei (CCN) closure during CRYSTAL-FACE, J. Geophys. Res., 108, 4633, doi:10.1029/2003JD003582, 2003.
Wang, J., Flagan, R. C., and Seinfeld, J. H.: A differential mobility analyzer (DMA) system for submicron aerosol measurements at ambient relative humidity, Aerosol Sci. Technol., 37, 46-52, 2003.

Wang, J.: Effects of spatial and temporal variations in aerosol properties on mean cloud albedo, J. Geophys. Res., 112, D16201, doi:10.1029/2007JD008565, 2007.

Zhang, Q., Jimenez, J. L., Canagaratna, M. R., Allan, J. D., Coe, H., Ulbrich, I., Alfarra, M. R., Takami, A., Middlebrook, A. M., Sun, Y. L., Dzepina, K., Dunlea, E., Docherty, K., DeCarlo, P. F., Salcedo, D., Onasch, T., Jayne, J. T., Miyoshi, T., Shimono, A., Hatakeyama, S., Takegawa, N., Kondo, Y., Schneider, J., Drewnick, F., Borrmann, S., Weimer, S., Demerjian, K., Williams, P., Bower, K., Bahreini, R., Cottrell, L., Griffin, R. J., Rautiainen, J., Sun, J. Y., Zhang, Y. M., and Worsnop, D. R.: Ubiquity and dominance of oxygenated species in organic aerosols in anthropogenically-influenced Northern Hemisphere midlatitudes, Geophys. Res. Lett., 34, L13801, doi:10.1029/2007GL029979, 2007. 